\section{Contadores de histórias: práticas discursivas e violência de gênero}

\author{
Storytelling: discursive practices and gender \\ violence
}

I Programa de Pós-graduação
em Saúde Coletiva,
Universidade do Vale do
Rio dos Sinos,
São Leopoldo, Brasil.
2 Departamento de
Psicología Social,
Universidad Autónoma
de Barcelona, Barcelona,
España.
Correspondência
S. N. Meneghel
Programa de Pós-graduação
em Saúde Coletiva,
Universidade do Vale do Rio
dos Sinos.
Av. Unisinos 950,
São Leopoldo, RS
93022-00o, Brasil.
meneghel@unisinos.br
smeneghel@hotmail.com

\section{Abstract}

This paper analyzes a storytelling workshop, an intervention based on the referential elements of oral narratives, held at an NGO in São Leopoldo, Rio Grande do Sul State, Brazil. The workshop was divided into three different stages: narration of a story with a focus on gender violence, a discussion based on the narrative, and an activity with body painting. The theoretical framework was based on discursive practices, and when workshop participants' discourse was assessed, at least two interpretive repertories were identified: one based on the gender category and the other on everyday life and recollections from participants' life stories. There was also considerable variety in the arguments, manifested in the contradictions and incongruence permeating the discourse. Narratives used as tools to work with abused women (especially for public health interventions) have received little attention thus far. In the current study, stories were analyzed as possible strategies to deal with gender inequalities, a powerful analytical tool for evaluating public health actions.

Discursive Practices; Narratives; Gender
Stela Nazareth Meneghel 1

Lupicínio Iñiguez 2

Este artigo analisa uma oficina de contadores de histórias realizada no Centro Ecumênico de Assessoria e Capacitação de São Leopoldo (CECA-SL), uma organização não governamental sediada na região do Vale do Rio dos Sinos, no Rio Grande do Sul (Meneghel SN, Farina O. Histórias de Resistência de Mulheres. Projeto de pesquisa apresentado ao Programa de Pós-graduação em Saúde Coletiva, Universidade do Vale do Rio dos Sinos; 2003). Esta oficina surgiu com base em uma proposta de contar histórias, em um grupo voluntário constituído por professores e alunos dos cursos de Psicologia e de Comunicação da Universidade do Vale do Rio dos Sinos (UNISINOS). O principal objetivo do grupo era o de contar histórias em diferentes coletivos. A estratégia de contar histórias transformou-se em tema de pesquisa, e foram realizadas várias oficinas de narrativas no período 2002-2004. Oficinas foram consideradas dispositivos de trabalho, determinados pelas práticas histórico-sociais, que buscam reforçar a autonomia dos participantes por meio da reflexão crítica e da reinvenção do cotidiano 1,2. Atividades coletivas fundamentadas em referenciais participativos como os da pesquisa ação $3,4,5$ e os da educação libertadora 6 as oficinas estimulam a construção de estratégias de resistência, por meio da crítica, da dialogicidade e da arte. Não se trata de grupos terapêuticos ou psicoterápicos, embora, em muitas situa- 
ções, as pessoas se beneficiem emocionalmente ao participar destas intervenções. Também não se trata de grupos de discussão porque no espaço das oficinas realizam-se atividades lúdicas e artísticas, onde se aposta na mudança e no empoderamento das pessoas. O trabalho com recursos tais como as artes plásticas, a música, o teatro, a dança tem sido explorado em oficinas voltadas para uma ampla variedade de temas e de coletivos: mulheres, pessoas em situação de violência, moradores de rua, portadores de sofrimento mental.

Gênero foi um tema gerador, por intermédio do qual foram escolhidas as histórias a serem narradas e eleitos tópicos para a discussão. Em relação a gênero, assumimos a posição que atribui ao patriarcado a manutenção do sistema de dominação/exploração das mulheres, sem refutar aspectos culturais, particularmente no que se refere à capacidade das mulheres de resistir aos padrões de dominação. Trabalhar com gênero pressupõe a desnaturalização das relações entre homens e mulheres e o entendimento de que a identidade sexual é construída histórica e socialmente. Gênero é um modo primordial de significar relações de poder, representa uma recusa ao essencialismo biológico e à hierarquia sexista. Além disso, coloca em pauta o aspecto relacional entre homens e mulheres e rompe com a postura de vitimização 7,8,9,10,11,12 considerando que as violências praticadas contra a mulher estão baseadas nas desigualdades sociais 13,14 .

Desde o seu início, o movimento feminista propôs a organização de grupos de reflexão para enfrentar as violências perpetradas contra as mulheres. Esses grupos se tornaram espaços de discussão nos quais as mulheres questionavam aspectos da ideologia patriarcal invisibilizados pela cultura 15. Para o movimento feminista, a questão primordial é política, ou seja, a de encontrar formas de combater a opressão das mulheres, por meio da denúncia e da intervenção em situações de vulnerabilidade. Psicólogas feministas construcionistas têm reconceituado sexo/gênero como um modo de estruturar relações de poder entre os sexos, mostrando o quanto homens e mulheres estão engajados em fazer gênero. Elas corporificam o projeto político de uma futura abolição do binarismo patriarcal, em um mundo onde sexo/gênero sejam irrelevantes e não sirvam como base de opressão/ dominação 16,17,18

Esta pesquisa se articula às perspectivas críticas em psicologia social, nas quais as narrativas assumem uma posição de centralidade, em que o mundo e as pessoas se constituem em função da construção lingüística e discursiva. O mundo é uma construção pautada nos significados, nele o conhecimento é produzido de modo compartilhado e interativo, respeitados os princípios da intersubjetividade, da indexalidade e da reflexividade. A psicologia social crítica ressalta o caráter político da ação social inseparável da produção de efeitos, das relações de poder e da dimensão ética 19,20,21,22.

Operamos com a ferramenta "contar histórias", pensando o contador de histórias como o interlocutor que ajuda o narrador a reconstruir sua história, retomando experiências das quais foi espoliado, construindo uma identidade e uma memória coletiva 23,24 . Todas as culturas conhecidas são contadoras de histórias e qualquer experiência humana pode ser expressa como narrativa. Não são apenas as narrativas que definem a cultura, mas a cultura orienta as narrativas elaboradas em seu interior. O interesse atual pelo estudo das narrativas pode ser visto como parte das transformações que seguiram a crise do conhecimento moderno. No campo da saúde e da psicologia social, ocorreu uma revalorização das narrativas como dispositivos de agenciamento de significados 25,26,27,28.

Ricoeur 24 afirma que miríades de seqüências se enlaçam para constituir narrações e, baseando-se em Aristóteles, utiliza a noção de mimese para descrever como a narração imita a vida. A mimese capta a vida em ação, é uma espécie de metáfora, que possibilita uma nova leitura para a realidade. O mundo está atravessado por narrativas e é precisamente este atravessamento que constitui o mundo. Narrações estão incrustadas na sociedade, elas se entrecruzam e dialogam entre si, outorgando realidade ao mundo em que vivemos 29,30 .

As memórias, intenções, histórias de vida, identidades pessoais são organizadas em padrões narrativos. Histórias não acontecem simplesmente, são contadas, embora nem sempre esteja explícito quem é e onde está o contador da história. Às vezes, o narrador é uma só pessoa, outras vezes a história é criada conjuntamente ou cooperativamente por um coro de vozes. De qualquer modo, cada história e cada palavra são polifônicas, seu significado é dado pelos incontáveis contextos onde apareceu antes, fato que Bakthin chamou de princípio dialógico do discurso ${ }^{31,32}$. A psicologia narrativa sustenta um enfoque de um eu narrador e um eu narrado, um eu que vai tecendo o discurso, traçando argumentos, urdindo a trama, construindo acontecimentos e criando significados 33. Narrar e contar são fatos intercambiáveis, daí a importância dada ao tecer do enredo na configuração narrativa, fazendo com que o mundo seja sempre temporal. $\mathrm{O}$ tempo torna-se tempo humano, na medida em que está articulado de modo narrativo 34 . 
As narrativas ajudam a enfrentar mecanismos de exploração/dominação como os relacionados ao gênero, à raça e à classe social. Ao contar e recontar histórias, o narrador resgata memórias, remodelando-as segundo a ótica do presente e dando outro significado às experiências $31,33,35,36,37$.

\section{Trajeto metodológico - contando histórias}

O projeto de pesquisa Histórias de Resistência de Mulheres foi uma intervenção fundamentada no referencial teórico das narrativas orais 4,23,38,39, com base no entendimento de que o discurso é uma prática social, linguagem em uso, atividade humana de criar sentido. A fala é considerada um trabalho humano e uma das mais poderosas formas de ação cooperativa 40,41,42. O conceito de discurso foi usado no sentido amplo, que abarca todos os tipos de interações verbais, formais e informais, e todo o tipo de textos escritos 43,44. Discursos podem ser interpretados por meio de textos, em um processo de explorar as conotações, alusões e implicações evocadas. São sistemas de declarações, emitidos por sujeitos posicionados, atravessados por contradições e historicamente localizados, que reproduzem relações de poder e possuem efeitos ideológicos, os quais, por sua vez, permitem a emergência de espaços de manobra e resistência 45 .

Para a análise do discurso, as entrevistas, como parte do processo de construção do conhecimento, são tratadas como peças de interação social, nas quais os entrevistadores contribuem tanto quanto os entrevistados. Seguindo a lógica de análise do discurso, as entrevistas são conduzidas de um modo ativo e intervencionista, há envolvimento do entrevistador, oferecendo oportunidade de argumentação e contra-exemplos, questionando afirmações, possibilitando o acesso a uma ampla variedade de argumentos e pensamentos que os participantes produzem fora das entrevistas 46,47. Da mesma forma que o entrevistador, o contador de histórias envolve-se com o grupo, intervém, conta histórias, dialoga, argumenta, em suma, interage ativamente com os ouvintes.

Na construção da pesquisa, tiveram lugar várias etapas: (1) mapeamento de coletivos que atuam com o tema da violência e gênero; (2) planejamento e implementação das oficinas e, (3) análise das narrativas.

\section{Mapeamento de coletivos que atuam com o tema da violência e gênero}

Nesta etapa foi feito contato e parceria com o CECA-SL, uma Organização Não Governamental (ONG) que tem como objetivo a assessoria a movimentos populares na área de ecumenismo, gênero e direitos humanos, tendo como ponto de partida a teologia da libertação e a sua hermenêutica popular. Após a anuência da organização, iniciamos uma etapa de discussão conjunta com alguns de seus representantes, objetivando a formulação de objetivos comuns e a explicitação dos princípios éticos da pesquisa.

\section{Planejamento e implementação das oficinas}

Na oficina analisada neste artigo, escolhemos para contar ao grupo uma história do folclore esquimó baseada em gênero e chamada "Pele de Foca" 48. A partir da história, houve espaço para discussão/reflexão sobre a narrativa e uma proposta de vivência usando pinturas corporais. Os grupos foram filmados, com permissão dos participantes. A equipe interdisciplinar de pesquisadores pertencia aos campos da saúde coletiva, psicologia e comunicação.

\section{Análise das narrativas}

\section{- Organização do corpus}

O primeiro momento da análise correspondeu à construção de um corpus reunindo a compilação das filmagens, incluindo as falas da equipe da pesquisa. A transcrição das falas ajuda a sistematizar o processo de análise das práticas discursivas em busca dos aspectos formais da construção lingüística, dos repertórios usados e da dialogia implícita na produção de sentidos 49 .

\section{- Pré-análise ou leitura flutuante das falas compiladas}

Essa etapa corresponde às sucessivas leituras do texto em busca das unidades básicas de comunicação ou dos enunciados $38,43,50$. As práticas discursivas têm como elementos constitutivos: a dinâmica - que são os enunciados orientados por vozes - e os conteúdos, os repertórios interpretativos. Durante a etapa da pré-análise marcamos o texto com o objetivo de identificar os enunciados ou unidades básicas de comunicação, que segundo Bakhtin são pautadas pelo interlocutor e não pela gramática, já que cada enunciado vai da pergunta de alguém até a 
finalização da resposta do outro. Enunciados são elos na cadeia de comunicação e não devem ser descontextualizados, pois, ao tirar uma sentença do enunciado que lhe dá suporte, roubamos-lhe o sentido 51 .

- Identificação dos repertórios interpretativos, considerados sistemas lingüísticos usados para caracterizar e avaliar ações, eventos e outros fenômenos

Compreende o conjunto de recursos tais como categorias, vocabulário, metáforas, usado na linguagem do dia a dia. Esses recursos se originam na comunidade lingüística onde fomos socializados e se transmitem por dispositivos e relações; usamos uma espécie de catálogo de termos e formas recorrentes de falar. Para a análise, não é suficiente identificar as diferentes formas de linguagem em abstrato, é necessário conhecer os usos e funções dos repertórios e os efeitos decorrentes de sua existência 33,43,46,47.

$\mathrm{Na}$ apresentação dos repertórios interpretativos, analisamos os diálogos em seqüências de turnos constituídas por dois falantes ou em linhas narrativas compostas por diversas elocuções de um mesmo ator. Optou-se por este recorte uma vez que se trata de uma oficina, em que os enunciados nem sempre correspondem à resposta, a um interlocutor, ou seja, as pessoas podem estar se referindo a um questionamento realizado vários turnos de conversação antes; outras vezes o narrador segue sua própria linha argumentativa, independente das outras falas, como se estivesse construindo sozinho o arcabouço de sua própria trama. Esta última situação não significa que o narrador esteja em uma posição solipsista, já que na confecção da narrativa ele/ela pode capturar e incorporar, no seu discurso, palavras, elocuções, mensagens circulantes no grupo.

\section{- Variabilidade nos repertórios}

Variabilidade nos repertórios evidenciada pelas incongruências no uso da linguagem e pelo fato de as pessoas construírem diferentes versões sobre um acontecimento, as quais permitem fazer novas leituras. A variação é uma conseqüência da grande quantidade de atos que podem ser performatizados por um mesmo ator enquanto fala. Analisar os discursos sob o ponto de vista da variabilidade significa apontar as similaridades e as exceções, as consistências e inconsistências, incluindo as negações que podem sinalizar o encobrimento de condutas "politicamente incorretas”. Além disso, faz parte do estudo da variabilidade, a identificação dos acentos, das entonações, dos silêncios, das lacunas, das inter- rupções, ou seja, todos os aspectos relacionados à modulação e construção de elocuções durante o diálogo. Incluir a variabilidade em uma análise significa respeitar a polissemia dos discursos, ao invés de homogeneizá-los ou reduzi-los 43,46,47.

\section{Marcas e feridas, cicatrizes e resistências - histórias}

Nesta pesquisa, a equipe dos contadores de histórias era constituída por cinco pessoas: duas professoras da UNISINOS, uma do campo da saúde coletiva e outra da comunicação e três alunos do curso de psicologia. Os participantes da ONG eram oito pessoas, duas delas com cargos de coordenação e as demais vinculadas a projetos sociais. Para preservar o anonimato dos participantes, demos a eles os nomes das musas gregas, pseudônimos que nos parecem adequados, visto que os poetas e narradores gregos invocavam as musas para inspirar suas narrativas. Assim, as pesquisadoras foram chamadas de Mnemosine (memória), Polímnia (mímica) e Érato (poesia lírica) e as oficineiras de Clio (história), Tália (comédia), Urânia (astronomia), Calíope e Terpsícore (eloqüência), Euterpe (poesia) e Melpêmone (tragédia). Os nomes dados aos homens foram Apolo e Orfeu (pesquisadores) e Pan (oficineiro), em alusão às figuras olímpicas masculinas ligadas à música e às artes. Na designação dos nomes, de alguma forma, contemplou-se a presença de alguma característica das musas ou dos deuses, no(s)/na(s) oficineiro/a(s).

A oficina aconteceu em três momentos, compreendendo a narrativa, a discussão da história e a realização de uma atividade artística. Nas oficinas de contadores de histórias, o ponto de partida é sempre uma história escolhida coletivamente, por exemplo, em um grupo de mulheres negras em situação de violência, escolhemos as histórias dos orixás da mitologia africana 52 com as quais elas poderiam reconstruir elementos da memória coletiva afro-brasileira.

O processo de análise iniciou com a organização de um corpus textual, para o qual não há regras ou receitas, mas como assinalam Wetherell \& Potter 46,47 consiste em desenvolver esquemas interpretativos tentativos, os quais por sua vez podem ser abandonados e revisados outra vez. O esquema interpretativo consiste na escolha de um tema ou foco de interesse que irá catalisar a construção do repertório. A escolha do tema ancora-se na presença de palavras, vocábulos, metáforas e figuras de linguagem relacionadas entre si e com o tema em questão.

$\mathrm{Na}$ análise desta oficina, percebemos o uso de pelo menos dois repertórios interpretativos: 
o de gênero, constituído pelo jargão de trabalho utilizado tanto pelos educadores populares, quanto pelos pesquisadores. O outro repertório que atravessou as oficinas foi o linguajar do dia a dia, das narrativas pessoais, das experiências de vida. De qualquer maneira, não podemos deixar de assinalar que a escolha desses repertórios é uma construção dos pesquisadores, ou seja, ela não se pretende definitiva, não significa que se tenha descoberto uma verdade ou que outros caminhos de interpretação não sejam possíveis.

$\mathrm{O}$ repertório de gênero foi partilhado por todo o grupo, tanto pela equipe da pesquisa quanto pelos oficineiros. De certo modo, podemos dizer que constituiu uma garantia de que um tema comum aproximava pesquisadores e educadores populares. Tal repertório expressa o jargão de trabalho, o repertório "técnico/empiricista" denominado por Gilbert \& Mulkay 44 ao abrir a caixa de Pandora da produção científica ocidental e averiguar que os cientistas utilizam dois tipos de repertório, um técnico e outro cotidiano, em que os fatos, muitas vezes, são ajustados para se adequarem ao modelo científico.

Nos últimos anos, gênero tem sido uma categoria presente nos discursos de militantes de movimentos sociais, implicando a adesão a ações propositivas contra as violências. O movimento feminista atribuiu à ideologia patriarcal a manutenção das desigualdades sociais ligadas a gênero, por meio do reforço ao binarismo sexo/gênero, valendo-se de uma lógica dicotômica cuja função principal é produzir hierarquias de desigualdade 12 . Atualmente, no Brasil, gênero é uma categoria considerada progressista tanto na Universidade quanto nas ONG; todos os falantes usaram o discurso de gênero, num momento ou noutro da oficina, fazendo questão de ressaltar a adesão a ele.

Ao se posicionar criticamente em relação ao sexismo/machismo, as mulheres afirmaram que são obrigadas a: "abdicar de si mesmas, não ter projetos, se desviar do seu rumo, abrir mão de suas coisas, cederem às vontades do homem, serem as únicas a ter responsabilidade com os filhos, viver em clausura, largar as pessoas que tu quer bem para levar uma vida que não é a tua, abrir mão dos teus interesses em função do outro, sentir pena do outro" (Clio, Urânia, Terpsícore). A violência foi definida por elas como: "sofrer, apanhar, ser espancada, apanhar do marido" (Clio, Urânia, Terpsícore) e foram incluídas no repertório de gênero. A violência foi descrita como um comportamento natural, uma norma transmitida de pais para filhos, dentro de um padrão de transmissibilidade - "nas casa que a gente visita tem uma regra (...) começa a sofrê, apanhá, sê espancada pelo pai e aí casa cedo, tem filho cedo e apanha do marido, os filhos também passam a apanhá, né, isso vai passando, de pai pra filho, e mesmo assim elas não conseguem passá prôs filho, educá de uma outra forma do sofrimento que elas tiveram" (Urânia). Essa forma de entender a violência perpetrada contra as mulheres, atualmente percebida como relacional, constituiu uma das incoerências no discurso das oficineiras.

No repertório de gênero, foram incluídas as alusões identitárias presentes nos enunciados dos educadores populares: as referências à ONG, aos programas desenvolvidos na entidade, às experiências com o Movimento de Alfabetização (MOVA) e às capacitações de Promotoras Legais Populares (PLP), desenvolvidos na instituição. Os oficineiros se percebem como grupo possuidor de uma identidade coletiva, construída em 25 anos de trabalho de educação popular, ligado a uma vertente religiosa de esquerda, amplamente reconhecida e respeitada na região.

Em relação à posição dos falantes, observamos que os coordenadores, tanto da pesquisa quanto da ONG, falaram em primeiro lugar. As mulheres foram construindo a argumentação e fazendo referências umas às outras, por meio do relato de experiências de trabalho, evidenciando a construção coletiva do discurso 53, na qual vários falantes formulam um enunciado cooperativamente.

Outro repertório usado nas oficinas foi o cotidiano, o da linguagem comum, constituído pelas conversas do dia a dia e pelas experiências pessoais. Nos enunciados marcados pela cotidianidade, notamos o uso de grande quantidade de dícticos 54 na primeira pessoa do singular ou na segunda pessoa, porém se referindo a si mesmos, como nas expressões: "tu sente que...", "tu sabe que...".

Para falar das violências que atravessam as vidas tanto das oficineiras quanto das mulheres atendidas por elas nas comunidades, elas usaram as metáforas de "marcas e roubo da pele", ambas extraídas da história "Pele de Foca". Assim, elas afirmaram: "eu vou falar das minhas marcas, é preciso que a gente se exponha” (Melpêmone). Nas narrativas biográficas, às vezes a violência de gênero era colocada fora, no "outro", às vezes, a violência estava dentro e aparecia nos fragmentos das histórias de vida e das violências sofridas. As mulheres contaram episódios de violência ligados às suas trajetórias pessoais e afirmaram que a violência de gênero acontece em qualquer classe social, escolaridade ou raça: " $a$ gente percebe muito isso nas mulheres [o roubo da pele], e não interessa o nível de escolaridade" (Clio). Neste depoimento, a narradora mostra a violência como um fenômeno que pode suceder a qualquer mulher, inclusive às participantes 
das oficinas. Em vários momentos, o discurso de gênero adquiriu a peculiaridade de uma autonarração biográfica, indicando como as histórias podem se constituir em dispositivos que ajudam os narradores a recuperar a memória individual e coletiva, discursiva e coletivamente construída. A memória ajuda a compor uma narração, estabelece uma conversação com o passado, mostra qual a chave para interpretá-lo e quais as credenciais que avaliam sua verossimilhança 30,55.

Ao contar pedaços de suas vidas, as mulheres entremearam os dois repertórios: o técnico e o pessoal. Da mesma forma que Gilbert \& Mulkay 44 haviam mostrado, os repertórios se mesclam no uso cotidiano, e os oficineiros misturaram o repertório de gênero com as narrativas autobiográficas. As metáforas referentes às "marcas" agenciaram a narração biográfica em uma exposição que iniciou de modo impessoal, na terceira pessoa do singular e, aos poucos, adquiriu singularidade. Mediante a decisão de contar sobre suas marcas pessoais, o "eu" narrador se constituiu em primeira pessoa, o que possibilitou aos narradores o poder para desconstruir a experiência de violência e refazer a própria história usando "os cacos do passado" de que fala Ricoeur. $\mathrm{Na}$ ação reconstrutiva, organizada no sentido da totalidade, nada é descartado, todos os elementos são aproveitados, os secretos, os sem sentido, os inferiores, os vergonhosos. Como apontado por Wetherell 56, histórias de vida são pedaços de ruínas biográficas, fragmentos de conhecimento, imagens e observações estéticas de caráter fragmentado e contraditório.

Ao desconstruir a história de vida para construí-la em outros referenciais, Melpêmone teceu uma linha argumentativa na qual recorreu a múltiplos exemplos, escolheu as palavras, narrou e tornou a narrar o mesmo fato, como que procurando a versão mais adequada e se esforçando para produzir descrições da realidade que parecessem racionais e justificáveis, de acordo com a descrição de Potter 57 sobre o processo de elaboração das narrativas. Nesta construção, a narradora tentou convencer o ouvinte (ou a si própria) sobre a pertinência dos atos que realizou. E nas múltiplas metáforas que foram sendo discursivamente produzidas, ela procurou dar um sentido para o passado. Desse modo, a construção da narrativa, não é um esquema de causa-efeito, mas a busca de um significado para a própria vida "então (...) assim (...), acho que isso tem uma razão de ser, acho que o segredo tá na forma da gente lidá com estas marcas" (Melpêmone).

Quando narramos, precisamos explicitar as seleções que fizemos em detrimento de outras partes do texto, aquilo que usamos e aquilo que descartamos, a multiplicidade de histórias alternativas, vistas pela posição do "eu crítico" 58 . Melpêmone, ao contar a história de vida, modificou, repensou, refez as contradições presentes na narrativa, enfrentando a natureza dilemática da linguagem e do pensamento ${ }^{45}$. Deixou claro, como assinalaram Cabruja et al. 29 , o quanto narrativas têm o poder de refazer as linhas argumentativas de vidas rompidas pelas violências e realçou o poder do contador de histórias, aquele capaz de desconstruir a trama já vivida e romper com as determinações para refazer a própria vida em outro patamar.

Outro aspecto presente nos discursos foi a variabilidade, que apareceu no caráter polissêmico das narrativas, nos sentidos divergentes ou antagônicos em um mesmo texto. A variabilidade discursiva pode ser inferida pela organização retórica da argumentação, nos detalhes lingüísticos (hesitações, reparo na elocução de palavras, escolhas léxicas), na variabilidade intra e intertextual 59, na natureza dilemática dos repertórios lingüísticos 60 e nas contradições 45. Uma forma de identificar as contradições, segundo Parker 45, é por meio das diferentes maneiras de descrever alguma coisa e na identificação de termos que revelam objeção a uma asserção ou terminologia. As contradições também podem evidenciar-se nas referências que os atores fazem a outros discursos, ou seja, os discursos podem conter sua própria negação.

A variabilidade atravessou os repertórios interpretativos dos atores implicados. Os oficineiros se posicionaram favoravelmente em relação ao caráter relacional da violência de gênero embora, ao mesmo tempo, afirmaram a possibilidade de transmissão intergeracional da violência e atribuíram a violência de gênero a comportamentos individuais como alcoolismo, drogadição ou a patologias. "Ele não era normal, ele devia ter um distúrbio mental” (Melpêmone). Outra incongruência consiste no entendimento de que violência pode acontecer com todas as mulheres, "independente do nível de escolaridade" (Clio) e, por outro lado, restringi-la aos pobres, como se houvesse uma geografia da violência, como se os pobres fossem as classes perigosas, e como se fosse verdadeiro o velho jargão determinista de que "elas não conseguem mudar" (Urânia), esquecendo das possibilidades sempre presentes de agenciamento e transformação das mulheres 12 .

No repertório do dia a dia, uma contradição que identificamos foi a que se deu entre a necessidade de "romper com a violência" e a asserção de que "sem a relação violenta não haveria o filho" (Melpêmone), validando a ideologia patriarcal que atribui às mulheres a responsabilidade 
pelo cuidado dos filhos, cimentando a permanência na relação violenta.

Uma contradição que nos surpreendeu foi a nossa, enquanto grupo de contadores de histórias. Ficamos perplexos ao constatar o quanto fomos contraditórios, à medida que a proposta formulada no projeto de pesquisa Histórias de Resistência de Mulheres era a de democratização do conhecimento e a intervenção foi organizada de modo tradicional. Queríamos fazer um trabalho fundamentado nos princípios de dialogicidade expressos por Freire 6, realizar uma intervenção cooperativa na qual romperíamos com a pretensa superioridade do pesquisador como "aquele que sabe" e com as posturas autoritárias das práticas em educação e saúde. Mas, em vários momentos predominou a diretividade da tarefa, ainda que tenham ocorrido momentos de crítica e de mudança. Billig ${ }^{60}$, falando sobre a natureza dilemática do discurso, mostra o quanto as manifestações de poder nos embaraçam e como muitas vezes exacerbamos desnecessariamente o igualitarismo.

O humor apareceu em brincadeiras e jogos de linguagem, facilitado pelas características de plasticidade que as oficinas proporcionam. A ironia é uma ferramenta poderosa que se concretiza dando um significado oposto à literalidade das palavras. É um recurso que questiona e solapa os discursos dominantes. Contar histórias produz prazer, tanto em ouvir quanto em contar. Além disso, o humor, a ironia e o riso são poderosos dispositivos para dissolver as convenções e atuar como armas mortais contra os jogos de poder, necessários na agenda política da psicologia social e nas intervenções sociais 61,62 .

\section{Finalizando a história...}

No percurso dessa pesquisa, exploramos possibilidades narrativas, fomentamos parcerias, construímos algumas estratégias de resistência e nos deparamos com os nossos próprios limites. Trabalhamos com repertórios interpretativos, entendendo-os como estratagemas que os falantes usam na linguagem em ação, sabendo que eles dão conta de apenas parte dos significados das interações ${ }^{63}$. Também trabalhamos com os aspectos contraditórios dos discursos, sabendo que eles contêm a sua negação e que as contradições apontam possibilidades de mudança.

A utilização da análise das práticas discursivas para avaliar oficinas em educação, saúde e gênero constituiu uma aproximação fecunda entre a psicologia social e a saúde coletiva. A psicologia discursiva tem evidenciado os aspectos construtivos da linguagem na interação social, ou seja, o quanto a realidade é discursivamente construída 33 . Esta perspectiva potencializa a compreensão do mundo e das interações sociais, constitui ferramenta de trabalho poderosa para intervir na saúde da população e enfrentar as desigualdades, incluindo as de gênero.

As práticas discursivas, em especial a vertente foucaultiana, mostram que os jogos de poder estão implicados na construção dos saberes e na produção de verdades normatizadas, encarregadas de julgar, classificar, controlar, vigiar e determinar modos de viver e de morrer. Ainda, segundo Foucault, não há poder sem resistência 64. Divisar os jogos de poder, contrapostos às resistências, permite questionar as práticas de saúde encarregadas de submeter, mas também perceber a possibilidade de nos colocarmos a serviço da população e ajudar a edificar "barricadas" 65 de resistência.

Quando inventamos o grupo de contadores de histórias, pensávamos que ele poderia constituir um dispositivo para alavancar mudanças e agenciar estratégias de resistência às violências. De fato, as histórias contadas em grupo trazem à tona experiências de vulnerabilidade, como a doença, a morte, a exclusão social, a violência. Ao compartilhar essas experiências, os participantes, em um primeiro momento, rememoram a história pessoal, depois reconstituem essa história do ponto de vista do presente, e por fim, falam sobre as estratégias de resistência e enfrentamento usadas no cotidiano, tornando-as, de certa maneira, coletivas.

Fazer pesquisa com enfoque participativo nos aproxima dos analistas críticos do discurso, cujas agendas de investigação estão focalizadas em questões socialmente relevantes, com o objetivo de usar o conhecimento como suporte para a ação política e para a conquista de mudanças sociais 66 . Esta perspectiva ressalta os efeitos sociais dos discursos, isto é, o quanto eles reproduzem, mantém, reforçam e, inclusive, questionam a ordem social. Entender os discursos como práticas sociais significa encarar a existência de relações dialéticas entre eventos discursivos socialmente construídos e estruturas sociais discursivamente marcadas 42 .

Acreditávamos, e ainda acreditamos, que grupos de mulheres contando histórias podem resistir a situações de violência, reconstruir suas histórias de vida e organizar-se em padrões diferentes aos propugnados pela sociedade ocidental. Contar histórias é um dispositivo de agenciamento de subjetividades fluidas, permeáveis, nômades, em um exercício de práticas subversivas 12,67 e de resolução coletiva de problemas 20,32 . 


\section{Resumo}

Este artigo analisa uma oficina de contadores de histórias, uma intervenção fundamentada nos referenciais das narrativas orais, que ocorreu em uma organização não governamental sediada no Município de São Leopoldo, Rio Grande do Sul, Brasil. A oficina foi construída em três momentos, compreendendo: a narração de uma história com o foco em violência de gênero, a discussão da narrativa e a realização de pinturas corporais. O referencial usado foi o das práticas discursivas e, nas falas dos oficineiros, foram identificados pelo menos dois repertórios interpretativos: um deles pautado na categoria gênero e o outro, ancorado na cotidianidade e na rememoração das histórias de vida dos participantes. Além dos repertórios, ressaltamos a variabilidade manifesta nas contradições e nas incongruências que permearam os diálogos presentes nas argumentações. As narrativas, enquanto ferramentas para trabalhar com mulheres em situação de violência, têm sido pouco exploradas, sobretudo como possibilidade de intervenção em saúde coletiva. Nesta pesquisa, as histórias foram analisadas como possíveis estratégias para enfrentar as desigualdades de gênero, mostrando-se uma ferramenta analítica poderosa para avaliar ações de saúde coletiva.

Práticas Discursivas; Narrativas; Gênero

\section{Referências}

1. Barros RB. Dispositivos em ação: o grupo. In: Baremblitt G, organizador. Saúde Loucura - subjetividade. v. 6. São Paulo: Editora Hucitec; 1997. p. 183-91.

2. Rauter C. Oficinas para quê? In: Amarante P, organizador. Ensaios - subjetividade, saúde mental, sociedade. Rio de Janeiro: Editora Fiocruz; 2000. p. 267-78.

3. Brandão CR. Pesquisa participante. Brasília: Editora Brasiliense; 1980.

4. Marinas JM, Santamarina C, organizadores. La historia oral: métodos y experiencias. Madrid: Mistral; 1999.

5. Morin A. Pesquisa ação integral e sistêmica: uma antropopedagogia renovada. Rio de Janeiro: DP\&A Editora; 2004.

6. Freire P. Pedagogia da autonomia: saberes necessários à prática educativa. São Paulo: Editora Paz e Terra; 1996.

7. Scott J. Gênero: uma categoria útil nas análises. História, Educação e Realidade 1990; 16:5-22.

\section{Colaboradores}

S. N. Meneghel e L. Iñiguez participaram da revisão de literatura, elaboração da metodologia, análise dos resultados e redação do artigo final.

\section{Agradecimentos}

Ao apoio financeiro da Coordenação de Aperfeiçoamento de Pessoal de Nível Superior (CAPES), pela bolsa (CAPES Bex 1455-05-2) concedida a Stela Nazareth Meneghel, durante a realização do estágio pós-doutoral no curso de Doutorado de Psicologia Social, Universidade Autônoma de Barcelona, sob a orientação de Lupicínio Iñiguez Rueda.

A autora agradece a acolhida e as facilidades disponibilizadas em todos os momentos e por todo o grupo de professores e funcionários do Doutorado de Psicologia Social, Universidade Autônoma de Barcelona.
8. Gregori MF. Cenas e queixas - um estudo sobre mulheres e relações violentas e a prática feminista. São Paulo: Editora Paz e Terra; 1992.

9. Saffioti H. Gênero e patriarcado. In: Castillo-Martin M, Oliveira S, organizadores. Marcadas a ferro. Brasília. Secretaria Especial de Políticas para as Mulheres; 2005. p. 35-76.

10. Grossi P, Aguinski B. Por uma nova ótica e uma nova ética na abordagem da violência contras mulheres nas relações conjugais. In: Grossi P, Verba G, organizadores. Violências e gênero: coisas que a gente não gostaria de esquecer. Porto Alegre: EDIPUCRS; 2001. p. 19-45.

11. Butler J. Cuerpos que importan: sobre los límites materiales y discursivos del "sexo". Barcelona: Editorial Paidós; 2002.

12. Pujal M. El feminisme. Barcelona: Editorial UOC; 2005.

13. Organização Mundial da Saúde. Violência contra a mulher e saúde no Brasil. São Paulo: Organização Mundial da Saúde/Universidade de São Paulo; 2003. 
14. Secretaria Especial de Políticas para as Mulheres. Programa de Prevenção, Assistência e Combate a Violência Contra a Mulher. Plano nacional - diálogos sobre a violência doméstica e de gênero: construindo políticas para as mulheres. Brasília: Secretaria Especial de Políticas para as Mulheres; 2003.

15. Bourdieu P. A dominação masculina. 2a Ed. Rio de Janeiro: Editora Bertrand Brasil; 2002.

16. Parker I, Shotter J, editors. Deconstructing social psychology. London: Routledge; 1990.

17. Wilkinson S. Prioritizing the political: feminist psychology. In: Ibañez T, Iñiguez L, editors. Critical social psychology. London: Sage Publications; 1997. p. 178-92.

18. Pereira VL. Gênero: dilemas de um conceito. In: Strey M, organizador. Gênero e cultura: questões contemporâneas. Porto Alegre: EDIPUCRS; 2004. p. 173-98.

19. Gergen KJ. The social constructionist movement in modern psychology. Am Psychol 1985; 40:266-75.

20. Ibañez T. Why a critical social psychology? In: Ibañez T, Iñiguez L, editors. Critical social psychology. London: Sage Publications; 1997. p. 27-41.

21. Ibáñez T. Municiones para disidentes. Barcelona: Gedisa Editorial; 2001.

22. Iñiguez L. Análisis del discurso: manual para las ciencias sociales. Barcelona: Editorial UOC; 2004.

23. Benjamin W, Horkheimer M, Adorno T. Textos escolhidos. São Paulo: Editora Abril Cultural; 1975 (Coleção Os Pensadores).

24. Ricoeur P. Tempo e narrativa. Tomo I. Campinas: Editora Papirus; 1994.

25. Gergen K. Realidades y relaciones. Aproximación a la construcción social. Barcelona: Editorial Paidós; 1994.

26. Bruner J. Actos de significado: más allá de la revolución cognitiva. Madrid: Alianza Editorial; 1990.

27. Alves PC, Rabelo M. Experiência de doença e narrativa. Rio de Janeiro: Editora Fiocruz; 1999.

28. Caprara A, Veras MSC. Hermenêutica e narrativa: a experiência de crianças com epidermólise bolhosa congênita. Interface Comun Saúde Educ 2004; 9:131-46.

29. Cabruja T, Iñiguez L, Vázquez F. Como construimos el mundo: relativismo, espacios de relación y narratividad. Anàlisi. Quaderns de Comunicació i Cultura 2000; 25:61-94.

30. Vázquez F. La memoria como acción social: relaciones, significados y imaginario. Barcelona: Editorial Paidós; 2001.

31. Brockmeier J, Harré R. Narrativa: problemas e promessas de um paradigma alternativo. Psicol Reflex Crít 2003; 16:525-35.

32. Ochs E. Narrativa. In: van Djik TA, organizador. El discurso como estructura y proceso: estudios sobre discurso I. Barcelona: Gedisa Editorial; 2003. p. 271-304.

33. Garay A, Iñiguez L, Martinez L. La perspectiva discursiva en psicología social. http://www. antalya.uab.es/liniguez/materiales/perspetiva \%20discursiva.pdf (acessado em Mai/2005).

34. Ferreira A, Grossi Y. A narrativa na trama da subjetividade: perspectivas e desafios. História Oral 2004; 7:41-59.
35. Sawaia SM. Narrativas orais e experiências: as crianças do Jardim Piratininga. In: Oliveira Z, organizadores. A criança e seu desenvolvimento: perspectivas para discutir a educação infantil. São Paulo: Cortez Editora; 2000. p. 31-49.

36. Meneghel SN, Barbiani R, Steffen H, Wunder AP, Roza MD, Rotermund J, et al. Impacto de grupos de mulheres em situação de vulnerabilidade de gênero. Cad Saúde Pública 2003; 19:955-63.

37. Meneghel SN, Barbiani R, Brener C, Teixeira G, Sttefen H, Silva LB, et al. Cotidiano ritualizado: grupos de mulheres no enfrentamento à violência de gênero. Ciênc Saúde Coletiva 2005; 10:111-21.

38. Bauer M, Gaskel G. Pesquisa qualitativa com imagem, texto e som. Rio de Janeiro: Editora Vozes; 2002.

39. Thompson P. A voz do passado. 3ạ Ed. São Paulo: Editora Paz e Terra; 2002.

40. Iñiguez L. De discursos, estructuras y análisis: ¿qué practicas? en qué contextos? In: Small Group Meeting: Critical Social Psychology. http:// antalaya.uab.es/liniguez/Materiales/003.pdf (acessado em Jan/2006).

41. Wetherell M. Themes in discourse research: the case of Diana. In: Wetherell M, Taylor S, Yates S, editors. Discourse theory and practice: a reader. London: Sage Publications; 2001; p. 14-28.

42. Rojo M. New developments in discourse analysis: discourse as social practice. Folia Linguistica 2001, XXXV:42-78.

43. Potter J, Wetherell M. Discourse and social psychology. London: Sage Publications; 1987.

44. Gilbert GN, Mulkay M. Opening Pandoras' box: a sociological analysis of scientists discourse. Cambridge: Cambridge University Press; 1984.

45. Parker I. Discourse dynamics: critical analysis for social and individual psychology. London: Rutledge; 1992.

46. Wetherell M, Potter J. Mapping the language of racism: discourse and the legitimation of exploitation. New York: Columbia University Press; 1992.

47. Wetherell M, Potter J. El análisis del discurso y la identificación de los repertórios interpretativos. In: Gordo AJ, Linaza JL, organizadores. Psicologías, discursos y poder. Madrid: Visor; 1996. p. 63-78.

48. Estès CP. Mulheres que correm com os lobos: mitos e histórias do arquétipo da mulher selvagem. Rio de Janeiro: Editora Rocco; 1997.

49. Spink MJ, organizador. Práticas discursivas e produção de sentidos no cotidiano - aproximações teóricas e metodológicas. São Paulo: Cortez Editora; 2004.

50. Minayo MC. O desafio do conhecimento: pesquisa qualitativa em saúde. Rio de Janeiro: Editora Hucitec; 1992.

51. Spink MJ. Linguagem e produção de sentidos no cotidiano. Porto Alegre: EDIPUCRS; 2004.

52. Ramão SR, Meneghel SN, Oliveira C. Nos caminhos de Iansã: cartografando a subjetividade de mulheres em situação de violência de gênero. Psicol Soc 2005; 17:79-87.

53. Martinez FD. Formulaciones colectivas y formulaciones mutuas: reconstrucciones de un conflicto social. In: Gordo AJ, Linaza JL, organizadores. Psicologías, discursos y poder. Madrid: Visor; 1996. p. 151-70. 
54. Levinson S. Pragmática. Barcelona: Teide; 1989.

55. Billig M. Discoursive, rethorical and ideological messages. In: McGarty C, Haslam A, editors. The message of social psychology. Oxford: Blackwell; 1997. p. 210-21.

56. Wetherell M. Identities, groups and social issues. London: Sage Publications; 1998.

57. Potter J. La representación de la realidad: discurso, retórica y construcción social. Barcelona: Editorial Paidós; 1998.

58. Clonely FM, Clandinin DJ. Relatos de experiencia e investigación narrativa. In: Larrosa J, organizador. Déjame que te cuente: ensayos sobre narrativa y educación. Barcelona: Editorial Laertes; 1995. p. 191-220.

59. Potter J. Discursive social psychology: from attitudes to evaluations. European Review of Social Psychology 1998; 9:233-66.

60. Billig M. Ideological dilemmas. London: Sage Publications; 1988.

61. Serra JC. Navegando entre narraciones: voces que construyen y socavan la credibilidad en el ámbito jurídico. Athenea Digital 2005; 8:109-28.
62. Ibañez T, Iñiguez L. Telling stories about storytellers. Athenea Digital 2002; 1:64-74.

63. Parker I. Discurso, cultura y poder en la vida cotidiana. In: Gordo AJ, Linaza JL, organizadores. Psicologias, discursos y poder. Madrid: Visor; 1996. p. 79-92.

64. Velasco M, Pujal M. Reflexiones en torno al suicidio: desestabilizando una construcción discursiva reduccionista. Athenea Digital 2005 7:133-47.

65. Ibañez T. Barricadas después de una crisis. In: Ibáñez T. Psicologia social construcionista. Guadalajara: Universidad de Guadalajara; 2001. p. 313-9.

66. Wetherell M. Debates in discourse research. In: Wetherell M, Taylor S, Yates S, editors. Discourse theory and practice: a reader. London: Sage Publications; 2001. p. 380-99.

67. Butler J. El genero en disputa: el feminismo y la subversión de la identidad. Barcelona: Editorial Paidós; 2001.

Recebido em 22/Mai/2006

Versão final reapresentada em 19/Dez/2006

Aprovado em 01/Mar/2007 